\title{
The effect of ageing on elastohydrodynamic friction in heavy duty diesel engine oils
}

\author{
Marcus Björling ${ }^{1}$, Kim Berglund ${ }^{1}$,Andrew Spencer ${ }^{2}$ and Roland Larsson ${ }^{1}$
}

\begin{abstract}
To further improve the efficiency of machine components found in automotive engine systems it is important to understand the friction generation in these components. Modeling and simulation of these components are a crucial part of the development process. Accurate simulation of the friction generated in these machine components is, amongst other things, dependent on a realistic lubricant rheology and lubricant properties, where especially the latter may change during ageing of the lubricant. Many modern heavy duty diesel engines are in operation for several hundred hours before the engine oil is changed. In this work, two engine oils, one 10W-30 and one 5W-20 have been aged in full heavy duty diesel engine bench tests for 400 and 470 hours respectively. This roughly corresponds to the amount of ageing these oils are subjected to between oil drains in field conditions. The aged oils were subjected to a number of oil analyses showing, among others, a maximum increase in oil viscosity of $12.9 \%$ for the $5 \mathrm{~W}-20$ oil and $5.5 \%$ for the 10W-30 oil, which is most likely primarily an effect of evaporation and oxidation. The aged oils were tested in a ball on disk test rig under elastohydrodynamic conditions where friction was measured and the performance was compared to fresh samples of the same oils. The results show that there is almost no difference in elastohydrodynamic friction when comparing the aged oils with the fresh oils. These results indicates that it is not necessary to include oil ageing in numerical EHD friction models as long as the oil is changed before the ageing has reached a critical level.
\end{abstract}

\section{Keywords}

Lubricant ageing, EHL, friction, antioxidant, lubricant, ball on disk, elastohydrodynamic

\section{Introduction}

The automotive industry is facing increasing restrictions in terms of emissions and is therefore spending considerable resources on research and development in several areas to reduce emissions. One area of research is lubricant technology. Lubricants play a vital part in reducing friction and provide cooling in a variety of machine components in a vehicle. It has been assessed that $33 \%$ of the fuel energy in a car is used to overcome friction, and that $30-35 \%$ of these friction losses originates from the engine system ${ }^{8}$. In heavy road vehicles and buses, $34 \%$ of the fuel energy is used to overcome friction, and approximately $18 \%$ of these losses originates from the engine system ${ }^{9}$.

One way to further reduce emissions in a vehicle is to improve the efficiency of the engine system by optimizing machine components and lubricants. Modeling and simulation of these components are a crucial part of the development process. Accurate simulation of the friction generated in these machine components is, amongst other things, dependent on a realistic lubricant rheology and lubricant properties, where especially the latter may change during ageing of the lubricant. Many modern heavy duty diesel engines are in operation several hundred hours before the engine oil is changed. The friction that is generated in elastohydrodynamically lubricated contacts found in for instance gears, rolling element bearings and cam followers is strongly dependent on the rheological properties of the lubricant. It is therefore of great interest to investigate the effect of ageing on engine oil rheological properties and tribological performance.

Previous studies have investigated oil degradation in a one cylinder petrol engine and seen large changes in viscosity and tribological performance from oil extracted from the top ring zone as well as the oil sump of the engine system ${ }^{10 ; 11}$. However, as far as the authors know, there have not been any studies performed under realistic operating conditions in heavy duty diesel engines on oil ageing and the effect on EHD friction.

In this work, two engine oils, one 10W-30 and one $5 \mathrm{~W}-20$, have been aged in full heavy duty diesel engine bench tests for 400 and 470 hours respectively. This roughly corresponds to the amount of ageing these oils are subjected to between oil drains in field conditions. The aged oils were tested in a ball on disk test rig under elastohydrodynamic (EHD) conditions where friction was measured and the performance was compared to fresh samples of the same oils. The antioxidant levels in the used oils were evaluated

\footnotetext{
${ }^{1}$ Division of Machine Elements, Department of Engineering Science and Mathematics, Luleå University of Technology, Luleå, Sweden

${ }^{2}$ Dynamics, Acoustics and Tribology, Engine Dynamics, Scania, Scania Technical Centre, 15187 Södertälje, Sweden
}

\section{Corresponding author:}

M. Björling, Division of Machine Elements, Department of Engineering Science and Mathematics, Luleå University of Technology, Luleå, SE97187 Sweden

Email: marcus.bjorling@ltu.se 
with RULER ${ }^{\circledR}$ (Remaining Useful Life Evaluation Routine) and the viscosities were measured of the fresh oil and during several steps of the ageing process. Several other measurements such as volatility, total base number (TBN), total acid number (TAN), fuel dilution and soot levels were also measured to better explain the nature of the ageing.

\section{Overall Methodology}

The following sections cover the test specimens and lubricants. It also contains information about how the different lubricant properties were measured. Finally, there is a description of how the experimental equipment for the friction tests and engine bench tests were set up, and how the experiments were performed.

\section{Test specimens and lubricant}

The test specimens for the ball on disk machine were produced in DIN 100Cr6 (AISI 52100) bearing steel and measured to a surface roughness, RMS of $25 \mathrm{~nm}$ for the balls and $35 \mathrm{~nm}$ for the disks, which gives a combined roughness of approximately $43 \mathrm{~nm}$. The surface roughness measurements were conducted in a Wyko NT1100 optical profilometer system from Veeco. The measurements were performed using 10x magnification and $1 \mathrm{x}$ field of view. The balls are grade 20 with a 13/16 inch $(20.63 \mathrm{~mm})$ outer diameter and a hardness of about 60 HRC. The disks have a 4 inch $(101.6 \mathrm{~mm})$ outer diameter, a circumferential grind (before polish) and are through hardened to about $60 \mathrm{HRC}$.

The lubricants used in the tests were two engine oils with two different viscosity levels, one 5W-20, and one 10W-30.

\section{Ball on disk tribotester}

The experiments were carried out with a Wedeven Associates Machine (WAM) 11, ball on disk test device. The lubricant is supplied at the center of the disk in an oil dispenser that distributes the lubricant across the disk surface. The lubricant is circulated in a closed loop from the oil bath, through a peristaltic pump to the oil dispenser at the center of the disk. The peristaltic pump is delivering approximately 180 $\mathrm{ml} / \mathrm{min}$. Three thermocouples are used in the test setup, one located in the oil bath, one in the outlet of the oil supply, and one trailing in the oil film close to the inlet region of the ball on disk contact. A more thorough description of the test rig and its features is presented in previous work ${ }^{4}$.

\section{Ball on disk test procedure}

The ball on disk test device was used to generate friction data from a series of tests under different operating conditions. In each test cycle, the entrainment speed was varied between 0.45 and $4.45 \mathrm{~m} / \mathrm{s}$ while the slide to roll ratio (SRR) was varied from -0.0002 to -0.49 . SRR is defined as the ball surface speed minus the disk surface speed, divided by the entrainment speed. All tests in this investigation were hence conducted with the disk having a higher surface speed than the ball. Both ball and disk specimens were cleaned with heptane and ethyl alcohol before starting the experiments for each of the test cases. All tests were performed with a load of $300 \mathrm{~N}$ which corresponds to a maximum Herzian pressure of $1.94 \mathrm{GPa}$. The tests were performed at three
Table 1. Investigated conditions

\begin{tabular}{lc}
\hline Lubricant & $5 \mathrm{~W}-20$ and $10 \mathrm{~W}-30$ \\
Temperature & 40,80 and $100^{\circ} \mathrm{C}$ \\
Contact load & $300 \mathrm{~N}$ \\
Maximum hertzian pressure & $1.94 \mathrm{GPa}$ \\
Entrainment speed, $U_{e}$ & 0.45 to $4.5 \mathrm{~m} / \mathrm{s}$ \\
Slide to Roll Ratio, SRR & 0.0002 to 0.49 \\
\hline
\end{tabular}

different temperatures; 40,80 and $100^{\circ} \mathrm{C}$. Before starting the experiments for each test case, the test device was warmed up to the desired operating temperature for approximately 60 minutes with lubricant circulation over both ball and disk to ensure thermal stability. When a stable temperature was reached, a $300 \mathrm{~N}$ load was applied and the machine was calibrated for pure rolling by adjusting spindle angle and positioning of the ball to ensure a condition of no spinning. These settings were then held constant for 20 minutes to ensure a mild run-in. Subsequently, the test cycle was started, wherein the load was kept at a constant value, and entrainment speed and slide to roll ratio were varied from the lowest to the highest value. The test cycle contains several loops where SRR is held constant for each loop and the entrainment speed is ramped from 4.5 to $0.45 \mathrm{~m} / \mathrm{s}$. In the first loop the SRR is held at 0.0002 and is then continuously increased with each loop until it reaches 0.49 . The temperature of the oil bulk and fluid adhered to the disk surface was typically deviating less than $\pm 1.5^{\circ} \mathrm{C}$ from the target temperature of 40,80 and $100{ }^{\circ} \mathrm{C}$ during testing. The results are shown as so called friction maps discribed in previous work $^{3 ; 4}$. A summary of the test conditions is found in Table 1.

\section{Engine tests}

The engine oils were run in a Scania V8 engine in an engine bench test through their standard endurance test cycle. The endurance test is a combination of idle, full load at different speeds and exhaust braking operating points, at both normal and elevated oil temperatures, and has been developed to promote accelerated ageing of the engine. The engine is put through the most severe conditions that might be seen with an end user. During testing the engine oil was changed every 400-500 hours which has been empirically found to lead to similar ageing of the oil that would be experienced in a customer vehicle between oil drains.

\section{Lubricant analysis}

The RULER ${ }^{\circledR}$ is a linear voltammetric technique designed to evaluate the relative amount of antioxidants of an aged lubricant sample compared to a fresh lubricant sample. The investigated lubricant is mixed with a solvent and an electrolyte. The measurement probe of the RULER ${ }^{\circledR}$ instrument is placed in the sample solution and voltage is increased linearly across the measurement probe. The oxidation current is measured as voltage increases during the test. Current peak heights can be used to indicate the concentration of an antioxidant and the voltage potential range is related to the type of antioxidant. The measurements were performed according to ASTM D6971.

The kinematic viscosity of the oil was measured using a glass capillary kinematic viscometer according to the 


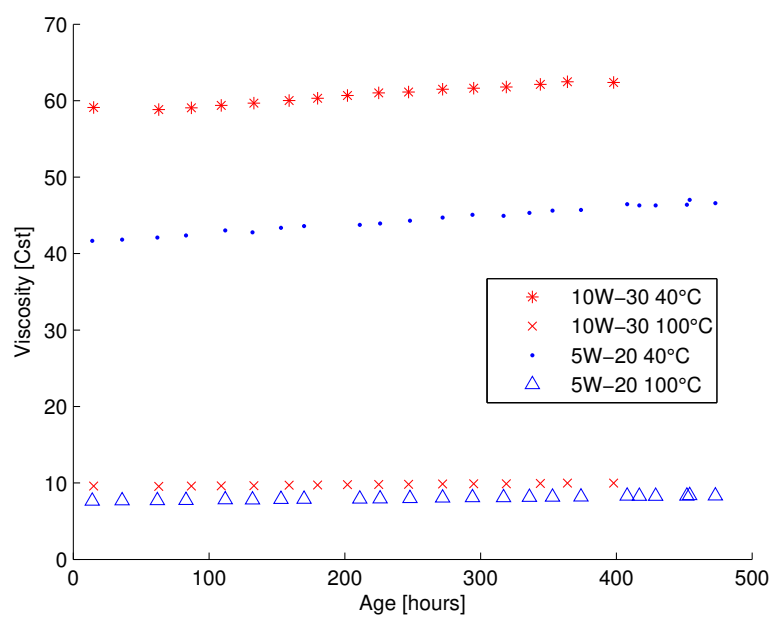

Figure 1. Kinematic viscosity of the $5 \mathrm{~W}-20$ and $10 \mathrm{~W}-30$ oils with ageing time

standards ASTM D446 (operating instructions of the viscometer) and ASTM D445 (test method for measuring viscosity). In a glass capillary viscometer fluid passes through a fixed-diameter orifice under the influence of gravity. The rate of shear is less than $10 \mathrm{~s}^{-1}$. The time taken for a specified volume of lubricant to flow through the capillary is measured at a controlled and known temperature. The kinematic viscosity is then a product of the measured time for the lubricant to flow through the capillary and a calibration constant of the viscometer. The test is run twice and the mean of the two values is taken as the final result. The dynamic viscosity is then calculated by multiplying the kinematic viscosity by the density.

The evaporative loss of the oils was evaluated by Noack volatility test, ASTM D5800. The total base number was evaluated according to ASTM D2896 and the total acid number by ASTM D664. The fuel dilution was evaluated according to ASTM D3524-04. The soot leveles were measured according to ASTM D7844.

\section{Results}

In this section, the results from the lubricant analysis are presented together with the results from the experimental friction measurements.

The results from the viscosity measurements are shown in Fig. 1. Both oils show an increase in viscosity with ageing time. For the $5 \mathrm{~W}-20$ oil the viscosity increased by $12.9 \%$ at $40^{\circ} \mathrm{C}$ and by $9.4 \%$ at $100^{\circ} \mathrm{C}$ at the end of the ageing process. For the $10 \mathrm{~W}-30$ oil the viscosity increase was $5.5 \%$ at $40^{\circ} \mathrm{C}$ and $4.1 \%$ at $100^{\circ} \mathrm{C}$ when the ageing was finished.

The results from the RULER $^{\circledR}$ measurements are presented in Figs. 2 and 3 for the 5W-20 and 10W-30 oils respectively. The RULER ${ }^{\circledR}$ measurements of a fresh lubricant sample compared to an aged lubricant sample are shown in each of the figures. The peaks of each curve represent different antioxidant species and it can therefore be observed that the $5 \mathrm{~W}-20$ lubricant contains three types of antioxidants, while the $10 \mathrm{~W}-30$ contains two types. The peak height indicates antioxidant concentration. Thus, the degradation of antioxidant species can be seen

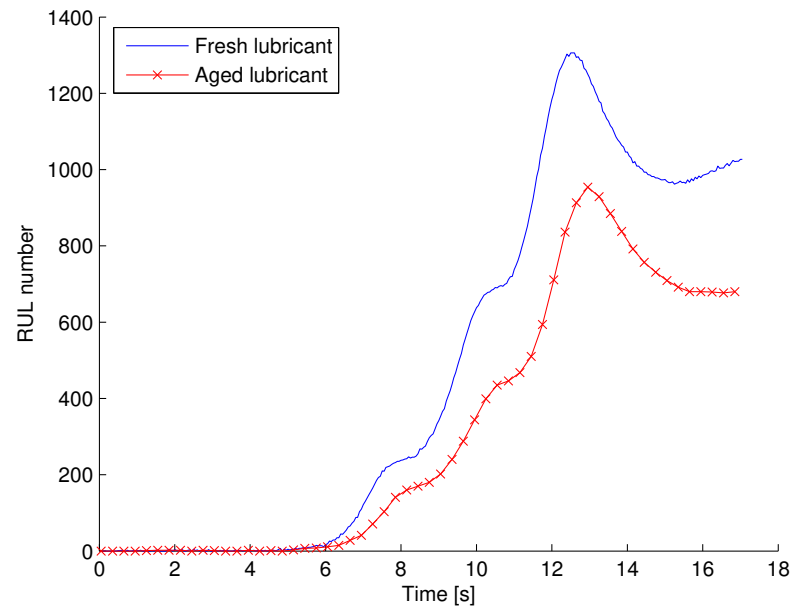

Figure 2. Antioxidant levels in $5 \mathrm{~W}-20$ in fresh lubricant and lubricant aged for 470 hours. The RUL value after ageing was measured to $67 \%$.

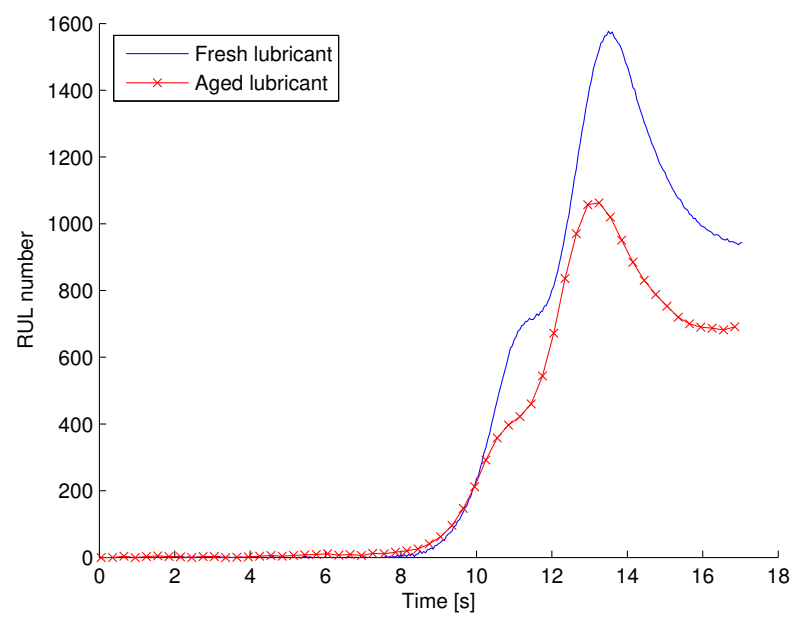

Figure 3. Antioxidant levels in $10 \mathrm{~W}-30$ in fresh lubricant and lubricant aged for 400 hours. The RUL value after ageing was measured to $73 \%$.

as lowered peak height of the aged lubricant compared to the fresh sample. The RUL value, i.e. the relative amount of antioxidants, was calculated by dividing the RULER ${ }^{\circledR}$ curve areas of the fresh and aged lubricant sample. RUL values after ageing were $67 \%$ and $73 \%$ for the $5 \mathrm{~W}-20$ and the $10 \mathrm{~W}-30$ respectively. Thus, both lubricants show sufficient oxidation protection even after ageing.

TAN decreased by $42 \%$ for the $5 \mathrm{~W}-20$ oil and $22 \%$ for the $10 \mathrm{~W}-30$ oil while TBN decreased by $27 \%$ for the $5 \mathrm{~W}-20$ oil and $13 \%$ for the $10 \mathrm{~W}-30$ oil. The soot levels increased to 0.07 weight $\%$ for the $5 \mathrm{~W}-20$ oil and 0.01 weight $\%$ for the $10 \mathrm{~W}-30$ oil. The fuel dilution remained below 0.4 weight $\%$ for both oils. The Noack volatility test showed an evaporative loss of 11.8 weight $\%$ for the 5W-20 oil and 9.3 weight $\%$ for the 10W-30 oil.

The results include friction coefficients for the measurements performed with the fresh 5W-20 and 10W-30 oils, and comparisons in percentage of the differences between the fresh oils and the aged oils. The results from the friction measurements of the $5 \mathrm{~W}-20$ and $10 \mathrm{~W}-30$ oils are presented 


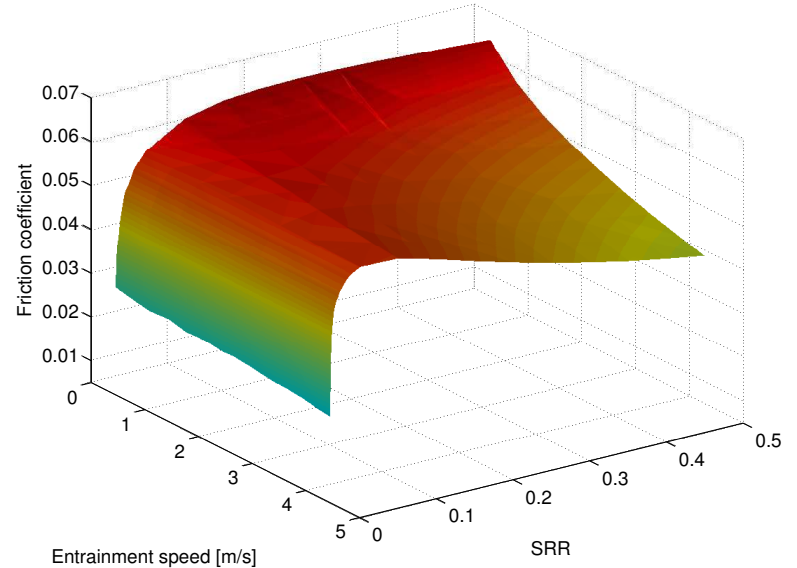

(a) $5 \mathrm{~W}-20,40^{\circ} \mathrm{C}$

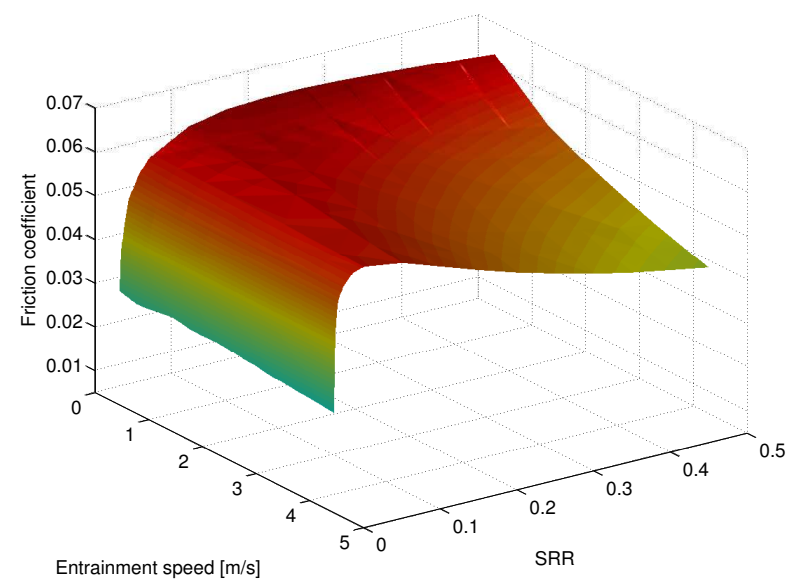

(c) $10 \mathrm{~W}-30,40^{\circ} \mathrm{C}$

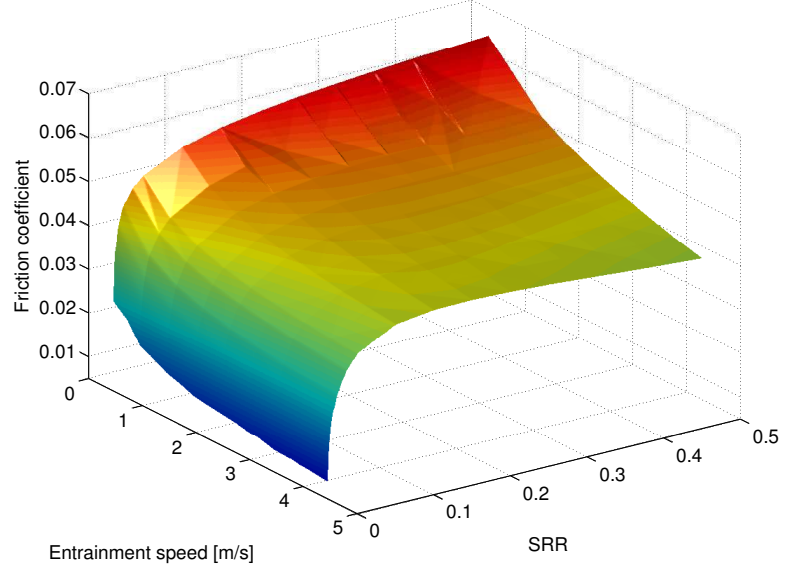

(b) $5 \mathrm{~W}-20,100^{\circ} \mathrm{C}$

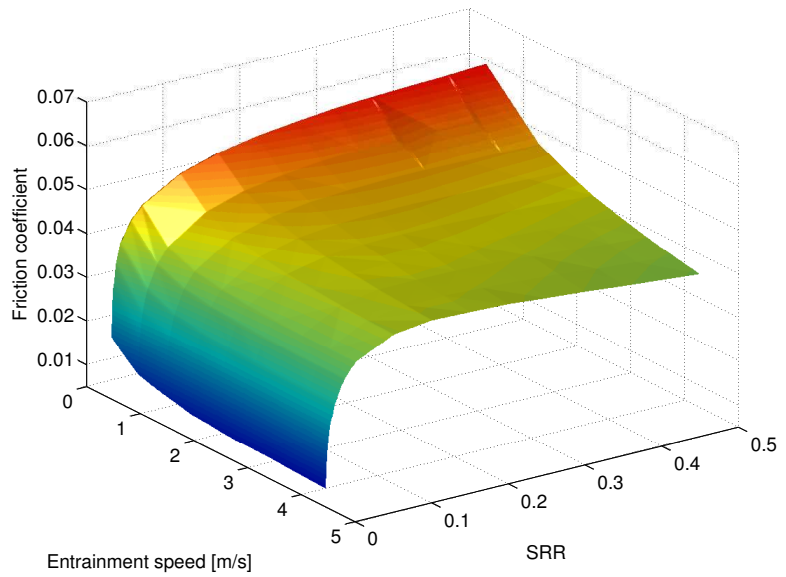

(d) $10 \mathrm{~W}-30,100^{\circ} \mathrm{C}$

Figure 4. 3D friction maps - Fresh oils, 5W20 and $10 \mathrm{~W} 30 @ 40$ and $100^{\circ} \mathrm{C}$

in Fig. 4 where Figs. 4(a) and 4(b) are from the friction measurements performed with the 5W-20 oil and Figs. 4(c) and 4(d) are from the friction measurements performed with the $10 \mathrm{~W}-30$ oil. In each figure the friction coefficient is plotted versus entrainment speed and SRR.

The authors believe that the majority of the friction measurements were performed in full film lubrication since the combined roughness of the specimens are quite low, around $43 \mathrm{~nm}$, as described in the overall methodology section. There may be some degree of asperity contact in the test performed at $100^{\circ} \mathrm{C}$ at the lowest entrainment speeds where the film thickness is at its lowest values. This may explain why the higher viscosity 10W-30 oil shows slighly lower friction coefficients than the lower viscosity $5 \mathrm{~W}-20$ oil in this region, see Figs 4(b) and 4(d). The minimum film thickness was calculated with the formula proposed by Chittenden et.al. ${ }^{13}$ to a value of $25 \mathrm{~nm}$ at the lowest entrainment speed for the $5 \mathrm{~W}-20$ oil at $100^{\circ} \mathrm{C}$, and to around $30 \mathrm{~nm}$ for the $10 \mathrm{~W}-30$ oil at $100^{\circ} \mathrm{C}$. Both of these oils have a calculated minimum film thickness that exceeds the combined roughness before reaching an entrainment speed of $1 \mathrm{~m} / \mathrm{s}$. The same oils have a minimum film thicknesses of $65 \mathrm{~nm}$ and $85 \mathrm{~nm}$ respectively at an entrainment speed of
$0.45 \mathrm{~m} / \mathrm{s}$ at $40^{\circ} \mathrm{C}$, thus clearing the combined roughness even at the lowest tested speed. Based on this formula the aged oils have even higher film thicknesses at the same conditions due to their higher bulk viscosities compared to the fresh oils.

All friction maps cover several different friction regimes; from the linear increase in friction at low SRRs, to the nonlinear region where the behaviour is non-Newtonian, where shear thinning and ultimately the limiting shear stress is dominating the friction coefficient. At even higher SRRs the friction starts to decrease due to a combination of shear thinning and thermal softening of the lubricant. Finally, at the lowest entrainment speeds there may be some asperity contacts between the surfaces and the friction coefficient is therefore a combination of hydrodynamic effects and asperity interaction. For a more thorough description of the friction regimes, see previous work ${ }^{3 ; 4}$.

Figure 5 shows the difference between the fresh oils and the aged oils in percentage. A positive number indicates that the fresh oil has a higher friction coefficient compared to the aged oil and vice versa for a negative number. Figs. 5(a) and 5(b) show the results for the fresh and aged 5W-20 oil and Figs. 5(c) and 5(d) show the results for the fresh and aged 10W-30 oil. 


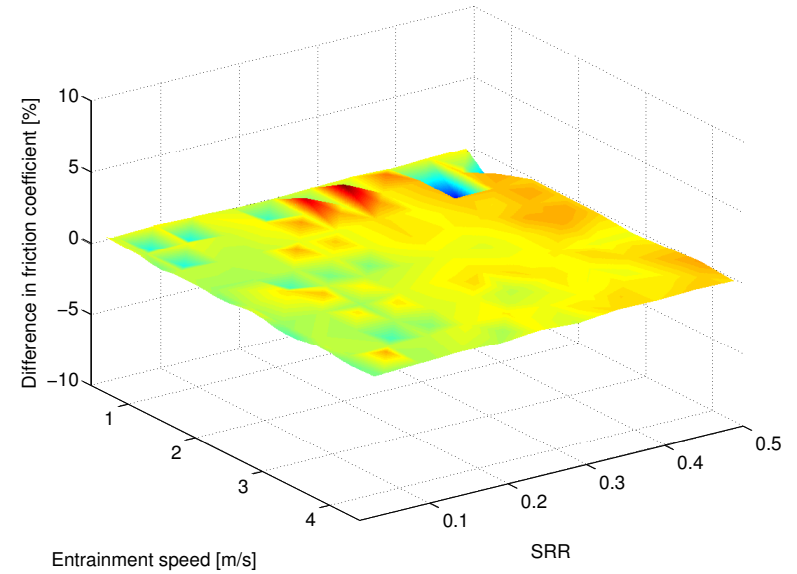

(a) $5 \mathrm{~W}-20$ - Difference between fresh and aged oil, $40^{\circ} \mathrm{C}$

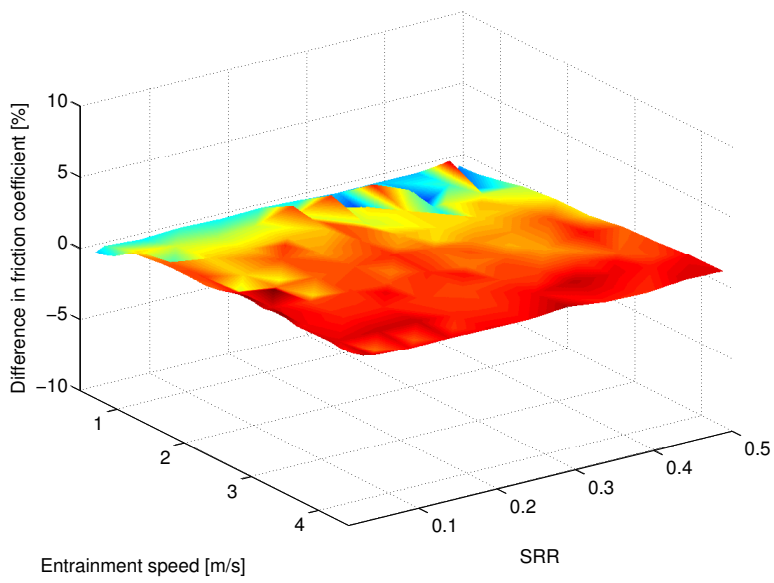

(c) 10W-30 - Difference between fresh and aged oil, $40^{\circ} \mathrm{C}$

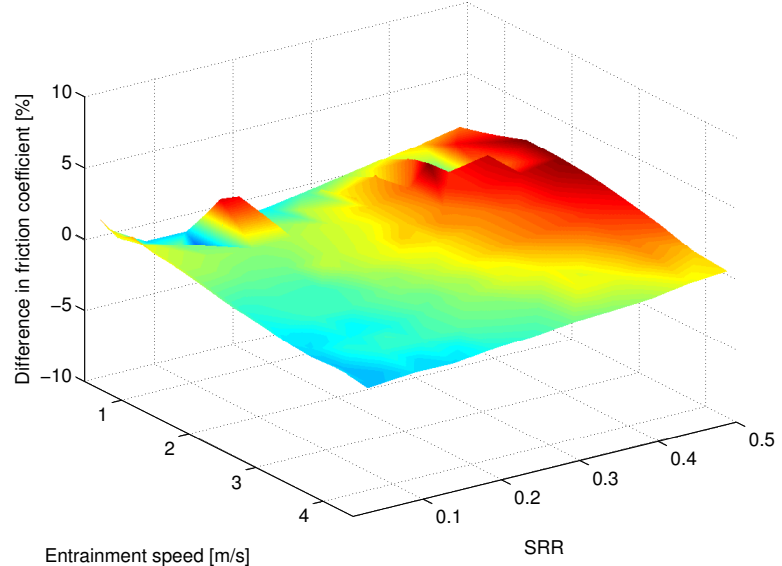

(b) $5 \mathrm{~W}-20$ - Difference between fresh and aged oil, $100^{\circ} \mathrm{C}$

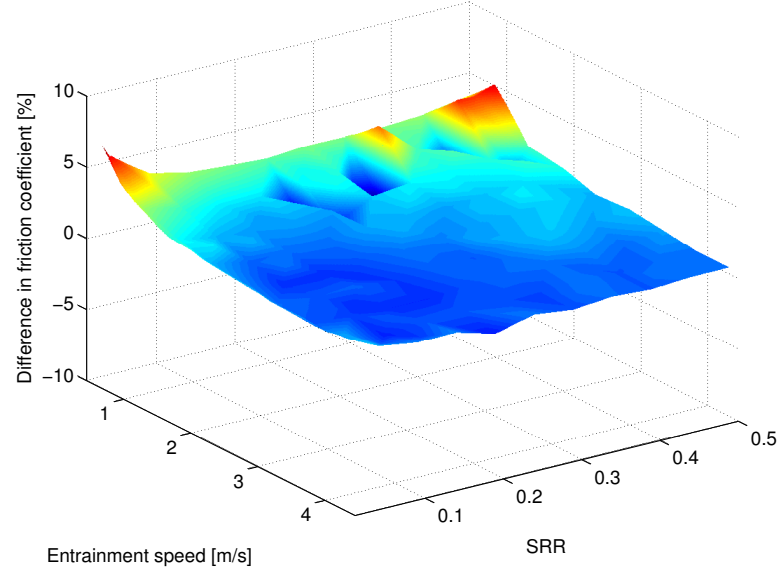

(d) $10 \mathrm{~W}-30$ - Difference between fresh and aged oil, $100^{\circ} \mathrm{C}$

Figure 5. 3D friction maps - Difference between fresh and aged oils, $5 \mathrm{~W}-20$ and $10 \mathrm{~W}-30 @ 40$ and $100^{\circ} \mathrm{C}$. A positive number indicates that the fresh oil has a higher friction coefficient compared to the aged oil and vice versa for a negative number.

The results for the tests performed at $80^{\circ} \mathrm{C}$ are not shown here to save space, but the results were showing the same trends as the tests performed at 40 and $100^{\circ} \mathrm{C}$. However, there are no signs of visible wear after the tests on either ball or disk.

\section{Discussion}

It is often stated that when an oil degrades in an operating engine the viscosity initially decreases due to a combination of fuel dilution and in case of fully formulated oils, mechanical degradation ${ }^{6 ; 7}$. Such behaviour is seen for the $10 \mathrm{~W}-30$ oil at both temperatures in Fig. 1, but not for the $5 \mathrm{~W}-20$ oil. It is possible that the $5 \mathrm{~W}-20$ oil still shows this kind of behaviour and that this would have been seen should shorter intervals between viscosity measurements have been used. The dominating trend for both oils is instead a viscosity increase where the viscosity is increased by a larger extent for the $5 \mathrm{~W}-20$ oil in comparison to the $10 \mathrm{~W}$ 30 oil. The increase in viscosity is most likely primarily caused by two different mechanisms. The first one being chemical reactions in the oil where the oxidized molecules are polymerized and thus increase the average molecular weight of the oil ${ }^{1 ; 5 ; 12}$. This process is accelerated by the high combustion temperatures and the effect of combustion gases passing through the piston rings as blow by and reacting with the oil in the crankcase. The second one is the evaporative loss where especially the smaller and lighter molecules are reduced thus increasing the viscosity of the lubricant. Fuel dilution and soot levels were both at such a low level that it is considered not to influence the results. The larger viscosity increase of the $5 \mathrm{~W}-20$ oil is most likely to a great extent explained by the fact that it was aged for 70 hours longer than the 10W-30 oil and has a higher evaporation loss in the Noack volatility test.

As indicated in Figs. 2 and 3 there are still plenty of antioxidant reserves left in the oils at the end of the motor bench tests. It is likely that the viscosity increase of the lubricants would have been much greater if the antioxidants would have been depleted.

As seen in Fig. 5 the EHD friction performance is almost unaltered comparing the fresh oils to the used oils, especially when a test temperature of $40^{\circ} \mathrm{C}$ were used. The changes are slightly higher at a temperature of $100^{\circ} \mathrm{C}$, but these variations 
are still in general less than $2.5 \%$. One explanation to the small difference in friction between the fresh and aged oils is that the change in viscosity with ageing is not substantial enough to cause significant changes in EHD friction. Also, especially in case of EHD contacts the kinetic viscosity measurements comparing the fresh and aged oils may not reflect the change in viscosity for the same oils at a higher shear rate. It has been shown that while a mechanically degraded oil may show a significant reduction in kinetic viscosity, the viscosity levels at higher shear rates, such as those found in the inlet of an EHD contact could be the same as for the fresh oil ${ }^{2}$. This means that the film thickness would be the same with the fresh and the mechanically degraded oil. If the same kind of normalization at higher shear rates happens with lubricants thickened by oxidation has not been explored as far as the authors know. This could be extended further to include also the even higher shear rates found inside of the EHD contact. Previous work has shown that if the viscosity and shear stress distributions in the contact is known, it is possible to compute friction with pretty good accuracy ${ }^{14}$. Therefore it could theoretically be a case where the bulk kinematic viscosity is changed, but the viscosity in the inlet and in the centre of the contact is unchanged, leaving both film thickness and friction unaltered.

The oils that have been analyzed in this investigation have been subjected to ageing in a motor bench test that corresponds to the ageing normally seen in oils used in the actual application before the drain intervals. These findings are important since they indicate that it is not necessary to include oil ageing in numerical EHD friction models as long as the oil is changed before the ageing has reached a critical level.

\section{In conclusion}

The purpose of this work was to investigate if oil ageing is an important parameter to consider in numerical EHD friction models for heavy duty diesel engines. One 5W-20 oil and one 10W-30 oil were aged in motor bench tests for 470 and 400 hours respectively. This roughly corresponds to the amount of ageing these oils are typically subjected to before the oil drain interval is reached. The aged oils were subjected to a number of oil analysis showing, among others, a maximum increase in oil viscosity of $12.9 \%$ for the $5 \mathrm{~W}-20$ oil and $5.5 \%$ for the $10 \mathrm{~W}-30$ oil, which is most likely primarily an effect of evaporation and oxidation. The antioxidant levels in the used oils were evaluated with RULER ${ }^{\circledR}$. These measurements indicate that the antioxidants are far from depleted in the aged oils. The aged lubricants and their fresh counterparts were tested in a ball on disk test rig under elastohydrodynamic conditions where friction was measured in a range of different entrainment speeds and slide to roll ratios. The results show almost no difference in elastohydrodynamic friction between the aged oils and the fresh oils. This indicates that it is not necessary to include oil ageing in numerical EHD friction models as long as the oil is changed before the ageing has reached a critical level.

\section{Acknowledgements}

The authors wish to thank Norrbottens Research Council for financial support.

\section{References}

1. Ali, A., Lockwood, F., Klaus, E.E., Duda, J.L., Tewksbury, E.J.: The chemical degradation of ester lubricants. ASLE Transactions 22(3), 267-276 (1979). DOI 10.1080/ 05698197908982924

2. Bair, S., Krupka, I., Sperka, P., Hartl, M.: Quantitative elastohydrodynamic film thickness of mechanically degraded oil. Tribology International 64, 33-38 (2013). DOI 10.1016/j. triboint.2013.02.032

3. Björling, M., Habchi, W., Bair, S., Larsson, R., Marklund, P.: Towards the true prediction of EHL friction. Tribology International 66, 19-26 (2013). DOI 10.1016/j.triboint.2013. 04.008

4. Björling, M., Larsson, R., Marklund, P., Kassfeldt, E.: Elastohydrodynamic lubrication friction mapping - the influence of lubricant, roughness, speed, and slide-to-roll ratio. Proceedings of the Institution of Mechanical Engineers, Part J: Journal of Engineering Tribology 225(7), 671-681 (2011). DOI 10.1177/1350650111403363

5. Blaine, S., Savage, P.E.: Reaction pathways in lubricant degradation. 2. n-hexadecane autoxidation. Industrial \& Engineering Chemistry Research 30, 2185-2191 (1991)

6. Flamberg, A., Koller, R.D., Herbeaux, J., Arsdale, W.E.V.: Mechanical degradation of multigrade oils in laboratory engine tests. SAE Technical Paper 942024 (1994). DOI 10.4271/ 942024

7. Herbeaux, J., Arsdale, W.V.: Mechanical degradation of multigrade engine oils. SAE Technical Paper 930690 (1993). DOI $10.4271 / 930690$

8. Holmberg, K., Andersson, P., Erdemir, A.: Global energy consumption due to friction in passenger cars. Tribology International 47, 221-234 (2012). DOI 10.1016/j.triboint. 2011.11.022

9. Holmberg, K., Andersson, P., Nylund, N.O., Mäkelä, K., Erdemir, A.: Global energy consumption due to friction in trucks and buses. Tribology International 78, 94-114 (2014). DOI 10.1016/j.triboint.2014.05.004

10. Lee, P.M., Priest, M., Stark, M.S., Wilkinson, J.J., Smith, J.R.L., Taylor, R.I., Chung, S.: Extraction and tribological investigation of top piston ring zone oil from a gasoline engine. Proceedings of the Institution of Mechanical Engineers, Part J: Journal of Engineering Tribology 220(3), 171-180 (2006). DOI 10.1243/13506501JET148

11. Lee, P.M., Stark, M.S., Wilkinson, J.J., Priest, M., Smith, J.R.L., Taylor, R.I., Chung, S.: The degradation of lubricants in gasoline engines: Development of a test procedure to evaluate engine oil degradation and its consequences for rheology. Tribology and Interface Engineering Series 48, 593-602 (2005)

12. Spearot, J.A.: Viscosity of severely oxidized engine oils. Industrial \& Engineering Chemistry Product Research and Development 13(4), 259-267 (1974). DOI 10.1021/ i360052a010

13. Chittenden, R., J., Dowson, D., Dunn, J. F., Taylor, C. M.,: A theoretical analysis of the isothermal elastohydrodynamic lubrication of concentrated contacts. I. Direction of lubricant entrainment coincident with the major axis of the Hertzian contact ellipse. Proceedings of the Royal Society of London. Series A, Mathematical and Physical Sciences 397, 245-269 (1985). DOI 10.1098/rspa.1985.0014 
14. Shirzadegan, M., Björling, M., Almqvist A., Larsson R.,: Low degree of freedom approach for predicting friction in elastohydrodynamically lubricated contacts Tribology International 94, 560-570 (1985). DOI 10.1016/j.triboint. 2015.10.010 